\title{
Surgical management of complete atrioventricular septal defect: Associations with surgical technique, age, and trisomy 21
}

\author{
Andrew M. Atz, MD, ${ }^{\mathrm{a}}$ John A. Hawkins, MD, ${ }^{\mathrm{b}}$ Minmin Lu, MS, ${ }^{\mathrm{c}}$ Meryl S. Cohen, MD, ${ }^{\mathrm{d}}$ \\ Steven D. Colan, MD, ${ }^{\mathrm{e}}$ James Jaggers, MD,${ }^{\mathrm{f}}$ Ronald V. Lacro, MD, ${ }^{\mathrm{e}}$ Brian W. McCrindle, MD, MPH, ${ }^{\mathrm{g}}$ \\ Renee Margossian, MD, ${ }^{\mathrm{e}}$ Ralph S. Mosca, MD, ${ }^{\mathrm{h}}$ Lynn A. Sleeper, $\mathrm{ScD},{ }^{\mathrm{c}}$ and L. LuAnn Minich, MD, ${ }^{\mathrm{b}}$ for the \\ Pediatric Heart Network Investigators
}

Objectives: We sought to evaluate the contemporary results after repair of a complete atrioventricular septal defect and to determine the factors associated with suboptimal outcomes.

Methods: The demographic, procedural, and outcome data were obtained within 1 and 6 months after repair of
a complete atrioventricular septal defect in 120 children in a multicenter observational study from June 2004 to 2006.

\begin{abstract}
Results: The median age at surgery was 3.7 months (range, 9 days to 1.1 years). The type of surgical repair was a single patch $(18 \%)$, double patch $(72 \%)$, and a single atrial septal defect patch with primary ventricular septal defect closure $(10 \%)$. The incidence of residual septal defects and the degree of left atrioventricular valve regurgitation (LAVVR) did not differ by repair type. The median interval of intensive care stay were 4 days, ventilation use 2 days, and total hospitalization 8 days. All were independent of the presence of trisomy 21 ( $80 \%$ of the cohort). The in-hospital mortality rate was $2.5 \%(3 / 120)$. The overall 6 -month mortality rate was $4 \%(5 / 120)$. The presence of associated anomalies and younger age at surgery were independently associated with a longer hospital stay. The age at repair was not associated with residual ventricular septal defect or moderate or greater LAVVR at 6 months. Moderate or greater LAVVR occurred in 22\% at 6 months, and the strongest predictor for this was moderate or greater LAVVR at 1 month (odds ratio, 6.9; 95\% confidence interval, $2.2-21.7 ; P<.001)$.

Conclusions: The outcomes after repair of complete atrioventricular septal defect did not differ by repair type or the presence of trisomy 21 . An earlier age at surgery was associated with increased resource use but had no association with the incidence of residual ventricular septal defect or significant LAVVR. (J Thorac Cardiovasc Surg 2011;141:1371-9)
\end{abstract}

The surgical techniques for repairing complete atrioventricular septal defects (AVSDs) have varied among surgeons and institutions. As perioperative care has improved, the age at repair has decreased. ${ }^{1}$ Coincident with the trend toward earlier AVSD repair has been an international demand for transparency regarding the outcomes data from each institution performing congenital heart surgery. AVSDs are one of the congenital heart defects whose outcomes have

\footnotetext{
From the Medical University of South Carolina, ${ }^{\text {a }}$ Charleston, SC; University of Utah, ${ }^{\mathrm{b}}$ Salt Lake City, Utah; New England Research Institutes, ${ }^{\text {c }}$ Watertown, Mass; Children's Hospital of Philadelphia, ${ }^{\mathrm{d}}$ Philadelphia, Pa; Children's Hospital Boston, ${ }^{\mathrm{e}}$ Boston, Mass; Duke University, ${ }^{\mathrm{f}}$ Durham, NC; University of Toronto, ${ }^{\mathrm{g}}$ The Hospital for Sick Children, Toronto, Ontario, Canada; and Columbia University Medical

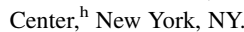

Supported by U01 grants from the National Heart, Lung, and Blood Institute (grants HL068269, HL068270, HL068279, HL068281, HL068285, HL068292, HL068290, HL068288, HL085057)

Disclosures: Authors have nothing to disclose with regard to commercial support. Received for publication April 27, 2010; revisions received July 13, 2010; accepted for publication Aug 1, 2010; available ahead of print Dec 16, 2010.

Address for reprints: Andrew M. Atz, MD, Department of Pediatrics, Division of Cardiology, Medical University of South Carolina, MSC 915, Rm 601, Children's Hospital, Charleston, SC 29425 (E-mail: atzam@musc.edu). $0022-5223 / \$ 36.00$

Copyright (C) 2011 by The American Association for Thoracic Surgery doi:10.1016/j.jtcvs.2010.08.093
}

been used to assess both the pediatric heart surgeon's skill and the institution's expertise. ${ }^{2}$ Controversy remains regarding the optimal reparative technique and whether trisomy 21 favorably or unfavorably affects the outcomes. In the present report, we evaluated the outcomes after repair of complete AVSD, with particular attention to the type of surgical repair, patient age at surgery, and the presence of trisomy 21 , and sought to identify the factors associated with suboptimal outcomes.

\footnotetext{
METHODS

From June 2004 and February 2006, the echocardiographic and clinical data were collected for children undergoing primary repair of a complete AVSD across the 7 North American centers constituting the National Heart, Lung, and Blood Institute-funded Pediatric Heart Network (see Appendix). The patients with single-ventricle physiology, associated tetralogy of Fallot, or an anomalous pulmonary venous connection were excluded. Prospective data were collected for 103 consecutive, eligible, and consenting patients who were included in a planned drug trial evaluating the use of angiotensin-converting enzyme inhibitors in children with left atrioventricular valve regurgitation (LAVVR) after AVSD repair. To enhance the completeness of the multicenter cohort of available subjects, we retrospectively added other patients who had been screened during the same period but had not been enrolled in the drug trial $(n=17)$, under a waiver of consent.
} 


$$
\begin{aligned}
& \text { Abbreviations and Acronyms } \\
& \text { ASD }=\text { atrial septal defect } \\
& \text { AVSD }=\text { atrioventricular septal defect } \\
& \text { ICU }=\text { intensive care unit } \\
& \text { LAVV }=\text { left atrioventricular valve } \\
& \text { LAVVR }=\text { left atrioventricular valve regurgitation } \\
& \text { VSD }=\text { ventricular septal defect }
\end{aligned}
$$

These patients had demographic characteristics similar to those who had been enrolled prospectively. All participating centers had received institutional review board approval (Clinical trials.gov Identifier: NCT00113698), and a National Heart, Lung, and Blood Instituteappointed data and safety monitoring board oversaw the present study.

\section{Clinical and Surgical Data Collection}

Using nomenclature from the Society of Thoracic Surgeons, only patients with a complete AVSD characterized by both a defect in the atrial septum just above a common $\mathrm{AV}$ valve and a nonrestrictive defect in the ventricular septum just below the AV valve were included. ${ }^{3}$ Data were collected at surgery and 1 and 6 months postoperatively. The operative reports from all patients were independently reviewed by 3 investigators who were unaware of the outcomes for uniformity in defect classification and details of the repair. Surgical data regarding the use of a single patch, double patch, or single atrial septal defect (ASD) patch with primary repair of the inlet ventricular septal defect (VSD) (Australian technique) were recorded. Standard techniques were used for each type of repair, and the details have been previously detailed. ${ }^{4-7}$ The single patch technique used pericardium for the single patch over both atrial and ventricular components. ${ }^{4}$ The double patch techniques used pericardium for the atrial component and a pericardium, a Dacron, or an expanded polytetrafluoroethelyene patch for the ventricular component. ${ }^{5}$ The "Australian," modified single patch technique used primary suture closure of the ventricular component and pericardium for the atrial component. ${ }^{6,7}$ Annuloplasty included any additional left atrioventricular valve (LAVV) surgery beyond cleft closure that resulted in annular diameter reduction. ${ }^{8}$ The bypass, crossclamp, and circulatory arrest times were obtained from the medical record.

Gender, the presence of trisomy 21, associated defects, age and weight at surgery, complications requiring intervention, and the duration of mechanical ventilation, intensive care, and total hospitalization were obtained from the medical records. The weight-for-age $\mathrm{z}$-scores were calculated using gender-specific reference values for trisomy $21^{9}$ and normal children, ${ }^{10}$ as appropriate. Growth failure was defined as a weight-for-age $\mathrm{z}$-score of less than -2 . The heart failure scores were determined using the Ross Heart Failure classification ${ }^{11}$ and were obtained 6 months after surgery. Cardiac medications were recorded at the 1-and 6-month echocardiograms.

\section{Echocardiographic Data}

For the 103 patients enrolled prospectively, the echocardiograms were performed within 1 month after repair and at the 6-month follow-up visit using a standard protocol. The echocardiograms were sent to a core laboratory, where measurements were made by a single observer. For the 17 patients enrolled retrospectively, only 1-month echocardiograms were available, with all measurements made by each center's echocardiographers. The left ventricular (LV) ejection fraction was calculated using Simpson's rule or the (5/6)*area*length method. ${ }^{12}$ LV dysfunction was defined as a LV ejection fraction of less than $55 \%$. The degree of LAVVR was subjectively graded as none/trace, mild, moderate, or severe according to the width of the color Doppler jets in relation to the surrounding chambers. ${ }^{13}$ LAVVR was considered significant if graded moderate or severe.
Color Doppler was also used to demonstrate any residual ASD or VSD, and diameters greater than $3 \mathrm{~mm}$ were considered significant. ${ }^{2}$ Pulsed Doppler interrogation of the LAVV inflow and LV outflow was performed, and a LAVV mean gradient of $7.5 \mathrm{~mm} \mathrm{Hg}$ or greater and LV outflow peak instantaneous gradient of $20 \mathrm{~mm} \mathrm{Hg}$ or greater were considered significant. After study conclusion, the degree of preoperative AVVR was retrospectively collected and graded similarly by each center's echocardiographers.

\section{Statistical Analysis}

The data are summarized using frequencies, medians, and means with the standard deviation, as appropriate. We compared the outcomes according to age at surgery, the presence or absence of trisomy 21 , and the type of surgical technique. Subgroup differences in the categorical variables were assessed using the chi-square test and Fisher's exact test. Subgroup differences in continuous variables were assessed using the $t$ test, analysis of variance, or nonparametric testing for highly skewed outcomes. The paired $t$ test and McNemar's test were used to assess the change in outcomes during the 6-month follow-up period. Nonparametric generalized additive modeling was used to identify nonlinear associations between covariates and outcomes. For age at surgery, we used piecewise linear regression analysis to determine the optimal cutpoint associated with particular outcomes. We applied a log transformation to the outcomes of length of stay, ventilator duration, and intensive care unit (ICU) stay to assess the association with potential predictors using linear regression analysis. Univariate associations between the outcome of at least moderate LAVVR and patient/surgical factors were identified using logistic regression analysis. All variables significant at the 0.20 level on univariate analysis were evaluated for inclusion in the multivariate regression models for the length of stay, ventilator duration, ICU stay, and at least moderate LAVVR. We used a test of interaction to assess whether the association of age at surgery $(\leq 2.5 \mathrm{vs}>2.5$ months) on the hospital outcomes varied with the number of concurrent procedures. Within the subgroups defined by the number of surgeries, unadjusted $P$ values are reported for the association between age at surgery and outcome. All analyses were performed using Statistical Analysis Systems statistical software, version 9 (SAS Institute, Cary, NC).

\section{RESULTS}

\section{Subjects and Clinical Outcomes at Surgery}

The study group included 120 patients $(80 \%$ with trisomy 21) who underwent repair at a median age of 3.7 months (Table 1). The median weight-for-age z-score at repair was -1.4 . Of the 120 patients, $37(31 \%)$ had growth failure (weight-for-age z-score $<-2$ ) and $10(8 \%$ ) weighed less than $3 \mathrm{~kg}$. Excluding a patent foramen ovale or small additional secundum ASD, additional cardiac defects requiring some concurrent surgical procedure were present in 58 patients $(48 \%)$. The most common concurrent procedure was ligation of an arterial duct in 53 patients (44\%). Other concurrent surgical procedures included repair of an aortic arch abnormality in 6 , closure of a remote VSD in 2 , venous baffle for anomalous systemic venous drainage in 2, plasty of a stenotic right upper pulmonary vein in 1 , and subaortic stenosis resection in 1 . A total of 7 patients $(6 \%)$ were returned to bypass during the initial operative procedure to address residual anatomic lesions; 3 to address significant LAVVR, 3 to address both LAVVR and a residual VSD, and 1 to address significant right-sided atrioventricular valve regurgitation.

Overall, 5 patients died (4\%). Of these 5 patients, 3 died before hospital discharge (age at repair was 15 days for 
TABLE 1. Results of 120 complete AVSD repairs by surgical technique

\begin{tabular}{|c|c|c|c|c|c|}
\hline Variable & Overall & Single & Double & Australian & $P$ Value \\
\hline Patients (n) & 120 & 21 & 87 & 12 & \\
\hline Age at AVSD repair (mo) & & & & & $.02 *$ \\
\hline Mean \pm SD & $3.8 \pm 1.8$ & $4.4 \pm 1.1$ & $3.8 \pm 2.0$ & $2.6 \pm 1.3$ & \\
\hline Median & 3.7 & 4.4 & 3.6 & 2.8 & \\
\hline Male $(\%)$ & 41 & 38 & 44 & 25 & .5 \\
\hline Trisomy $21(\%)$ & 80 & 91 & 83 & 42 & $.004 *$ \\
\hline Zone of apposition "cleft" closure $(\%)$ & 93 & 91 & 94 & 92 & .6 \\
\hline Annuloplasty (\%) & 24 & 14 & 30 & 0 & $.03 *$ \\
\hline Bypass time (min) & $112 \pm 36$ & $131 \pm 26$ & $110 \pm 38$ & $90 \pm 25$ & $.005 *$ \\
\hline Crossclamp time (min) & $82 \pm 31$ & $95 \pm 23$ & $81 \pm 33$ & $62 \pm 19$ & $.01 *$ \\
\hline Circulatory arrest (yes) & 8 & 19 & 6 & 8 & .1 \\
\hline $\begin{array}{l}\text { Concurrent surgery, excluding PFO/small } \\
\text { ASD }(\%)\end{array}$ & & & & & .7 \\
\hline 0 & 52 & 67 & 49 & 42 & \\
\hline 1 & 42 & 29 & 44 & 50 & \\
\hline 2 & 6 & 5 & 6 & 8 & \\
\hline 3 & 1 & 0 & 1 & 0 & \\
\hline Total ICU stay (d) & & & & & .8 \\
\hline Mean \pm SD & $8.6 \pm 16.8$ & $6.2 \pm 9.7$ & $9.0 \pm 18.5$ & $9.1 \pm 14.4$ & \\
\hline Median & 4 & 4 & 4 & 4 & \\
\hline Total ventilator use (d) & & & & & .8 \\
\hline Mean \pm SD & $6.0 \pm 14.9$ & $4.1 \pm 8.3$ & $6.3 \pm 16.1$ & $7.2 \pm 16.2$ & \\
\hline Median & 2 & 2 & 2 & 2 & \\
\hline Total hospital stay (d) & & & & & .1 \\
\hline Mean \pm SD & $13.2 \pm 20.4$ & $10.4 \pm 13.6$ & $15.3 \pm 22.3$ & $15.3 \pm 16.1$ & \\
\hline Median & 7 & 7 & 9 & 9 & \\
\hline Death by 6 mo (n) & $5(4.2)$ & $0(0)$ & $4(4.6)$ & $1(8.3)$ & .6 \\
\hline Reoperation by 6 mo (n) & $5(4.2)$ & $2(9.5)$ & $2(2.3)$ & $1(8.3)$ & .2 \\
\hline
\end{tabular}

a patient with duodenal atresia, 17 days for a patient with aortic arch obstruction, and 1.9 months for a patient with trisomy 21 and significant growth failure). The in-hospital deaths occurred 3 months, 2.3 months, and 5 days after repair. The 2 patients who died after hospital discharge had undergone repair at age 3.7 months and 5 months, and the deaths were attributed to pulmonary hypertension (2 and 5 months after discharge). Early reoperation (within 6 months of the initial surgery) was needed only for significant LAVVR and was performed in 5 patients ( 4 were $<2.5$ months old at the initial surgery; 1 of these patients died in-hospital, as reported at the beginning of this paragraph).

The median interval of mechanical ventilation, ICU stay, and hospitalization was 2 days (range, 1-100 days), 4 days (range, 1-127 days), and 8 days (range, 4-128 days), respectively. In-hospital complication data were recorded for the 103 prospectively enrolled patients, of whom 42 $(41 \%)$ had at least 1 complication (Table 2$)$.

\section{Clinical Outcomes Assessed at 1 and 6 Months}

The 17 screened patients who were added retrospectively, the 5 patients who died, and 13 patients who were alive but did not return for follow-up had no detailed clinical or echocardiographic re-evaluation data available at 6 months. In addition, 2 patients had technically unacceptable echocardiograms as determined by the core laboratory. Therefore, of the original cohort of 120 patients, 85 clinical data pairs and 83 echocardiographic data pairs were available to explore the potential changes over time between 1 and 6 months after surgery.

At 1 month postoperatively, the cardiac medications included angiotensin-converting enzyme inhibitors in 27 $(23 \%)$, digoxin in $13(11 \%)$, diuretics in $114(96 \%)$, and $\beta$-blockers in $5(4 \%)$ of 119 patients. By 6 months of follow-up, the use of angiotensin-converting enzyme inhibitors had decreased to $16 \%(14 / 85)$, diuretics to $20 \%(17 / 85)$, and digoxin to $2 \%(2 / 85)$; no patient was taking a $\beta$-blocker. Overall, growth had improved by 6 months of follow-up (weight-for-age $\mathrm{z}$-score $-1.5 \pm 1.2$ within 1 month of surgery vs $-0.7 \pm 1.0$ at 6 months, $P<.0001$ ), and the prevalence of growth failure had decreased from $31 \%$ to $11 \%(P<.001)$. The change in the weightfor-age $\mathrm{z}$-score was similar between those with and without trisomy $21(+0.7 \pm 1.1 \mathrm{vs}+1.2 \pm 0.8, P=.08$; Table 3$)$. Using the Ross heart failure scoring system, 79 patients were in class I, 3 were in class II, and 3 were in class III at 6 months after surgery. 
TABLE 2. Complications requiring treatment in 103 patients

\begin{tabular}{lcr}
\hline \multicolumn{1}{c}{ Complications* } & Frequency & $\%$ \\
\hline Infection & 11 & 11 \\
$\quad$ Bacterial positive sepsis & 6 & \\
Wound infection & 3 & \\
RSV bronchiolitis & 1 & \\
Clostridium difficile diarrhea & 1 & 14 \\
Pleural effusion & 14 & 6 \\
Pericardial effusion & 6 & 15 \\
GI complication, including NEC & 15 & \\
Arrhythmia & 9 & \\
$\quad$ Atrial flutter & 3 & \\
Junctional ectopic tachycardia & 1 & \\
Ventricular tachycardia & 5 & \\
Complete heart block & 0 & 2 \\
Cardiopulmonary resuscitation & 4 & 5 \\
Delayed sternal closure & 2 & 2 \\
Intubated $>2$ wk postoperatively & 5 & 2 \\
Renal failure (elevated creatinine $>7$ d) & 2 & \\
Vocal cord injury & 2 &
\end{tabular}

$R S V$, Respiratory syncytial virus; $G I$, gastrointestinal; $N E C$, necrotizing enterocolitis. *Complications were not mutually exclusive.

\section{Echocardiographic Outcomes}

Residual shunts were common, but most were small. At the echocardiogram performed within 1 month after surgery, $17(16 \%)$ of 105 patients had a residual ASD but only 1 was greater than $3 \mathrm{~mm}$. Of 117 patients, 56 (48\%) had a residual ventricular shunt, 9 of which were greater than $3 \mathrm{~mm}$. By 6 months, no patient had an ASD greater than $3 \mathrm{~mm}$ and 1 had a VSD of $3 \times 4 \mathrm{~mm}$. The prevalence of left ventricular dysfunction was relatively common early after surgery but had improved significantly by 6 months after surgery $(35 \%$ vs $10 \%, P<.001)$. No patient had LAVV stenosis or left ventricular outflow obstruction at either follow-up point. The prevalence of moderate or greater LAVVR did not change significantly with time: $24 \%$ within 1 month and $22 \%$ at 6 months. On multivariate analysis, the strongest predictor of important LAVVR at 1 month was a greater number of in-hospital complications (odds ratio $1.4,95 \%$ confidence interval $1.0-1.9, P=0.03$ ). The only predictor of important LAVVR at 6 months was moderate or greater LAVVR at 1 month (odds ratio, 6.9; $95 \%$ confidence interval, 2.2-21.7; $P<.001$ ).

\section{Comparison of Surgical Technique}

Double patch closure was the most widely used technique for repair in $87(72 \%)$ of 120 patients, followed by single patch closure in 21 patients $(18 \%)$ and the Australian technique in $12(10 \%)$, although the repair type varied by center $(P=.002$; Table 1$)$. The repair type was also associated with age, with the Australian technique performed in younger patients $(2.6 \pm 1.3$ months old, $P=.02)$ compared with the single ( $4.4 \pm 1.1$ months old $)$ or double patch $(3.8 \pm 2.0$ months old) techniques. The single patch technique was used more frequently in patients with trisomy 21 , and the
TABLE 3. Results stratified by trisomy 21 status

\begin{tabular}{|c|c|c|c|}
\hline \multirow[b]{2}{*}{ Variable } & \multicolumn{2}{|c|}{ Trisomy 21} & \multirow[b]{2}{*}{$\begin{array}{c}P \\
\text { Value }\end{array}$} \\
\hline & $\begin{array}{c}\text { Yes } \\
(\mathbf{n}=96)\end{array}$ & $\begin{array}{c}\text { No } \\
(n=24)\end{array}$ & \\
\hline Age at AVSD repair (mo) & $3.8 \pm 1.5$ & $3.7 \pm 2.8$ & .9 \\
\hline Male $(\%)$ & 41 & 42 & 1.0 \\
\hline \multicolumn{4}{|l|}{ Surgical management } \\
\hline Patch technique $(\%)$ & & & $.004 *$ \\
\hline Single & 20 & 8 & \\
\hline Double & 75 & 63 & \\
\hline Australian & 5 & 29 & \\
\hline $\begin{array}{l}\text { Zone of apposition "cleft" } \\
\text { closure (\%) }\end{array}$ & 95 & 88 & .4 \\
\hline Annuloplasty (\%) & 24 & 25 & 1.0 \\
\hline Bypass time (min) & $115 \pm 37$ & $100 \pm 30$ & .07 \\
\hline Return to bypass $(\%)$ & 4 & 13 & .2 \\
\hline Crossclamp time (min) & $83 \pm 32$ & $77 \pm 28$ & .4 \\
\hline Circulatory arrest (yes) & $6(6)$ & $4(17)$ & .1 \\
\hline $\begin{array}{l}\text { Concurrent surgery, excluding } \\
\text { PFO/ASD }(\%)\end{array}$ & 50 & 46 & .4 \\
\hline In hospital complication (\%) & 38 & 54 & .2 \\
\hline In-hospital complications (n) & $0.7 \pm 1.1$ & $1.4 \pm 1.8$ & $.05^{*}$ \\
\hline Total ICU stay (d) (median) & $8 \pm 17$ (4) & $11 \pm 17(4)$ & 6 \\
\hline $\begin{array}{l}\text { Total ventilator use }(\mathrm{d}) \\
\text { (median) }\end{array}$ & $6 \pm 15(2)$ & $8 \pm 16(2)$ & .8 \\
\hline Total hospital stay (d) (median) & $13 \pm 18(8)$ & $19 \pm 28(9)$ & .4 \\
\hline Reoperation by 6 mo (n) & $2(2)$ & $3(13)$ & .06 \\
\hline Death by 6 mo (n) & $4(4)$ & $1(4)$ & 1.0 \\
\hline \multicolumn{4}{|l|}{ Growth } \\
\hline $\begin{array}{l}\text { Weight-for-age z-score at } \\
\text { surgery }\end{array}$ & $-1.3 \pm 1.0$ & $-2.4 \pm 1.1$ & $<.001 *$ \\
\hline $\begin{array}{l}\text { Weight-for-age } \mathrm{z} \text {-score }<-2 \text { at } \\
\text { surgery }(\%)\end{array}$ & 21 & 71 & $<.001^{*}$ \\
\hline Weight-for-age z-score at $6 \mathrm{mo}$ & $-0.6 \pm 1.0$ & $-1.3 \pm 0.8$ & $.008 *$ \\
\hline $\begin{array}{l}\text { Weight-for-age } \mathrm{z} \text { score }<-2 \\
\text { at } 6 \mathrm{mo}(\%)\end{array}$ & 7 & 27 & $.05 *$ \\
\hline $\begin{array}{l}\text { Change in weight-for-age } \\
\text { z-score at } 6 \text { mo }\end{array}$ & $+0.7 \pm 1.1$ & $+1.2 \pm 0.8$ & .08 \\
\hline \multicolumn{4}{|l|}{ Echocardiographic findings (\%) } \\
\hline Residual ASD at $1 \mathrm{mo}$ & 14 & 30 & .09 \\
\hline Residual ASD at 6 mo & 4 & 0 & 1.0 \\
\hline Residual VSD at $1 \mathrm{mo}$ & 47 & 52 & .7 \\
\hline $\begin{array}{l}\text { Residual VSD at } 6 \text { mo } \\
\text { Moderate/severe LAVVR }\end{array}$ & 11 & 20 & .4 \\
\hline Preoperative & 17 & 38 & $.05 *$ \\
\hline At $1 \mathrm{mo}$ & 21 & 38 & .1 \\
\hline At $6 \mathrm{mo}$ & 20 & 33 & .3 \\
\hline
\end{tabular}

VSD, Ventricular septal defect; $L A V V R$, left atrioventricular valve regurgitation; other abbreviations as in Table $1 . *$ Statistically significant.

Australian technique was used least in patients with trisomy $21(P=.004)$. The bypass times were significantly longer for the single patch $(131 \pm 26$ minutes, $P=.005)$ compared with the double patch $(110 \pm 38$ minutes) and Australian (90 \pm 25 minutes) techniques. The crossclamp times were also longer with the single patch technique $(95 \pm 23$ minutes, $P=.01$ ) compared with the double patch 
TABLE 4. Results stratified by age at repair

\begin{tabular}{|c|c|c|c|}
\hline Variable & $\begin{array}{c}\text { Age } \leq 2.5 \mathrm{mo} \\
(\mathrm{n}=25)\end{array}$ & $\begin{array}{c}\text { Age }>2.5 \mathrm{mo} \\
(\mathrm{n}=95)\end{array}$ & $\begin{array}{c}P \\
\text { Value }\end{array}$ \\
\hline Male $(\%)$ & 52 & 38 & .3 \\
\hline \multicolumn{4}{|l|}{ Surgical management } \\
\hline $\begin{array}{l}\text { Zone of apposition "cleft" } \\
\text { closure }(\%)\end{array}$ & 86 & 95 & .2 \\
\hline Annuloplasty (\%) & 28 & 23 & .6 \\
\hline Double orifice mitral valve $(\%)$ & 0 & 4 & 6 \\
\hline Patch technique $(\%)$ & & & $.04 *$ \\
\hline Single & 4 & 21 & \\
\hline Double & 76 & 72 & \\
\hline Australian & 20 & 7 & \\
\hline Bypass time (min) & $111 \pm 48$ & $112 \pm 33$ & 1.0 \\
\hline Return to bypass (\%) & 8 & 5 & .6 \\
\hline Crossclamp time (min) & $82 \pm 41$ & $82 \pm 28$ & 1.0 \\
\hline Circulatory arrest & $5(20)$ & $5(5)$ & $.03 *$ \\
\hline $\begin{array}{l}\text { Concurrent surgery, excluding } \\
\text { PFO/ASD (n) }\end{array}$ & $0.8 \pm 0.8$ & $0.5 \pm 0.6$ & .06 \\
\hline In-hospital complication $(\%)$ & 56 & 37 & .1 \\
\hline In-hospital complications (n) & $1.6 \pm 2.0$ & $0.6 \pm 0.9$ & $.02 *$ \\
\hline Total ICU stay (d) (median) & $16 \pm 24(6)$ & $7 \pm 14(4)$ & $.002 *$ \\
\hline $\begin{array}{l}\text { Total ventilator use }(\mathrm{d}) \\
\text { (median) }\end{array}$ & $14 \pm 24(5)$ & $4 \pm 11(2)$ & $.006^{*}$ \\
\hline Total hospital stay (d) (median) & $24 \pm 26(12)$ & $12 \pm 18(8)$ & $.005^{*}$ \\
\hline Reoperation by 6 mo (n) & $4(16)$ & $1(1)$ & $.007 *$ \\
\hline Death by 6 mo (n) & $3(12)$ & $2(2)$ & .06 \\
\hline \multicolumn{4}{|l|}{ Growth } \\
\hline $\begin{array}{l}\text { Weight-for-age z-score at } \\
\text { surgery }\end{array}$ & $-1.3 \pm 1.2$ & $-1.6 \pm 1.1$ & .3 \\
\hline $\begin{array}{l}\text { Weight-for-age } \mathrm{z} \text {-score }<-2 \\
\text { at surgery }(\%)\end{array}$ & 28 & 32 & .8 \\
\hline Weight-for-age $\mathrm{z}$-score at $6 \mathrm{mo}$ & $-0.9 \pm 0.9$ & $-0.7 \pm 1.0$ & .4 \\
\hline $\begin{array}{l}\text { Weight-for-age } \mathrm{z} \text {-score }<-2 \\
\text { at } 6 \mathrm{mo}(\%)\end{array}$ & 19 & 9 & .4 \\
\hline $\begin{array}{l}\text { Change in weight-for-age } \\
\text { z-score at } 6 \text { mo }\end{array}$ & $0.5 \pm 1.1$ & $0.8 \pm 1.0$ & .3 \\
\hline \multicolumn{4}{|l|}{ Echocardiographic findings ( $\%)$} \\
\hline Residual ASD at 1 mo & 22 & 15 & .5 \\
\hline Residual ASD at 6 mo & 0 & 4 & 1.0 \\
\hline Residual VSD at $1 \mathrm{mo}$ & 52 & 47 & .7 \\
\hline Residual VSD at $6 \mathrm{mo}$ & 13 & 13 & 1.0 \\
\hline $\begin{array}{l}\text { Preoperative moderate/severe } \\
\text { LAVVR }\end{array}$ & 24 & 20 & .8 \\
\hline $\begin{array}{l}\text { Moderate/severe LAVVR at } \\
1 \mathrm{mo}\end{array}$ & 25 & 24 & 1.0 \\
\hline $\begin{array}{l}\text { Moderate/severe LAVVR at } \\
6 \mathrm{mo}\end{array}$ & 13 & 25 & .5 \\
\hline
\end{tabular}

Abbreviations as in Tables 1 and 3. *Statistically significant.

( $81 \pm 32$ minutes) or Australian (62 \pm 19 minutes) techniques. No patient with a single patch closure required repeat bypass compared with $5(6 \%)$ of 87 with a double patch and $2(17 \%)$ of 12 with the Australian technique $(P=.1)$. The zone of apposition or cleft was closed in $93 \%$ and the difference was not significant across repair types. The prevalence of residual ASD and VSD was not different among the surgical techniques. The percentage of subjects with significant LAVVR was not different across the repair types at 1 or 6 months after surgery. The total ICU days, days of ventilator use, and days in the hospital and mortality and need for reoperation by 6 months did not differ by repair type, even after adjusting for age at repair.

\section{Comparisons by Presence of Trisomy 21}

Trisomy 21 was present in $96(80 \%)$ of the 120 patients (Table 3). Age at surgery, gender, race, and ethnicity were similar in those with and without trisomy 21 . As stated previously, the repair types differed by trisomy 21 status, most notably with more repairs using the Australian technique in the non-trisomy 21 group ( $29 \%$ vs $5 \%$ ). The hospital courses were similar, with the exception of the number of in-hospital complications (greater in the non-trisomy 21 group). The mortality rate at 6 months was identical at $4 \%$, but a trend was seen toward more reoperations in the first 6 months for those without trisomy $21(13 \%$ vs $2 \%$, $P=.06)$. Moderate or severe LAVVR was more likely in the non-trisomy 21 group before AVSD surgery. However, the prevalence of LAVVR did not differ at 1 and 6 months after surgery. Using the trisomy 21 or normal growth standards, as appropriate, patients without trisomy 21 had significantly lower weight-for-age $\mathrm{z}$-scores $(-2.4 \pm 1.1$ vs $-1.3 \pm 1.0, P=.001)$ and a greater prevalence of growth failure $(71 \%$ vs $21 \%, P<.01)$ at repair than those with trisomy 21 . This difference persisted at both 1 and 6 months of follow-up, and, although both groups improved in growth, no significant difference was seen in the degree of improvement by group during the first 6 months after repair.

\section{Comparison by Age at Repair}

We found that adverse outcomes were negatively correlated with age at repair from birth to about 2.5 months but did not vary by age after 2.5 months (Table 4 ). When we assessed age as a dichotomous variable, we found that adverse outcomes such as a longer hospital stay, longer ICU stay, longer ventilator use, and greater complication rate were seen in those patients who had undergone repair before 2.5 months of age comparison with those who had undergone repair after 2.5 months of age (Table 4 ). A trend was seen toward greater mortality by 6 months in those younger than 2.5 months ( $12 \%$ vs $2 \%, P=.06)$, and the percentage of subjects requiring reoperation within the first 6 months was greater for those 2.5 months old or younger at surgery $(16 \%$ vs $1 \%, P=.007)$. Also, differences were in the surgical repair technique, with a greater percentage of repairs using the Australian technique for those 2.5 months old or younger. A greater percentage of younger subjects had circulatory arrest $(20 \%$ vs $5 \%)$. The growth parameters, prevalence of residual defects, and prevalence of moderate to severe LAVVR were similar between the younger and older cohorts. 

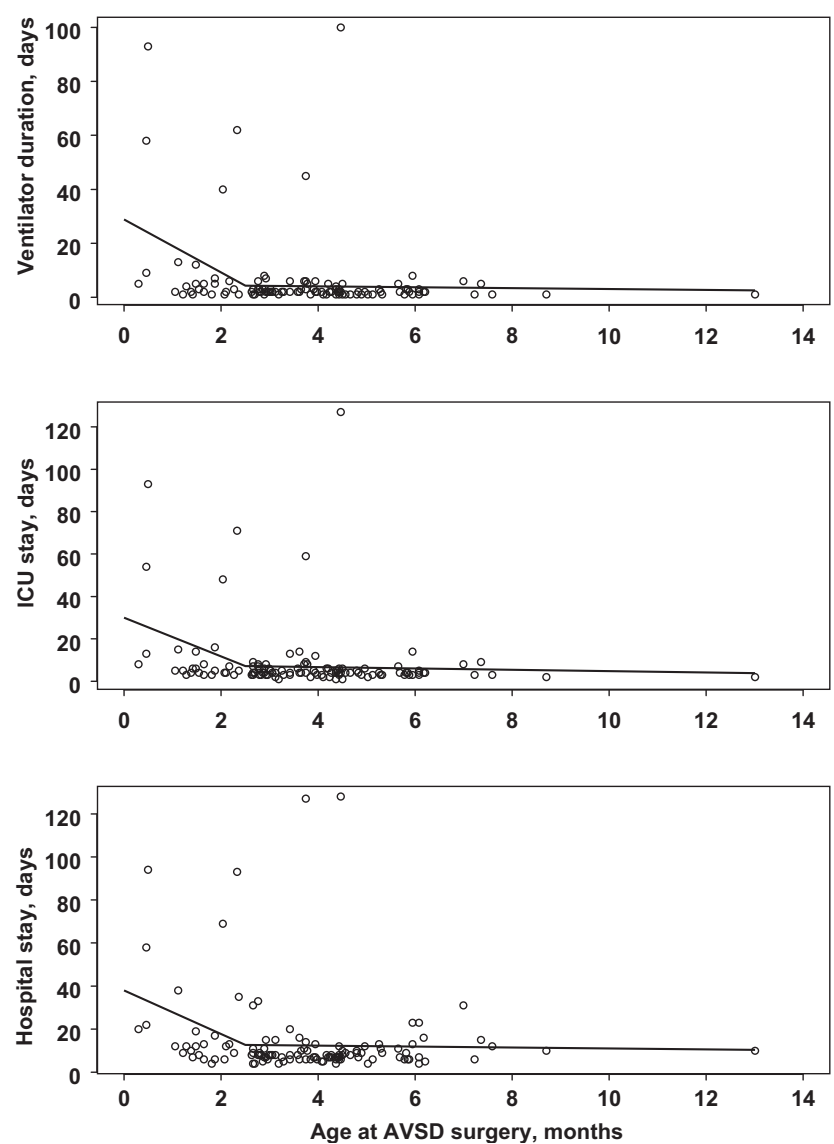

FIGURE 1. Piecewise regression fit for ventilator duration, intensive care unit $(I C U)$ stay, and hospital stay by age at surgery. Solid line indicates predicted values from regression versus age at surgery. Each outcome correlated negatively with age at surgery from birth to about 2.5 months but did not vary by age after 2.5 months.

\section{Factors Associated With Increased Resource Use}

The number of ventilator days, ICU days, and hospital days exhibited a dramatic right-skew. Those who had undergone repair at 2.5 months old or younger had a longer duration of mechanical ventilation and longer ICU and total hospital stays (Figure 1 and Table 4). We hypothesized that the relationship between these 3 outcomes and the number of surgeries performed concurrently with AVSD repair might be dependent on the age at surgery. We found a significant interaction for all 3 outcomes (all $P<.01$ ). In those 2.5 months old or younger at surgery, the resource use increased with each additional surgery, particularly for those with 2 or more concurrent procedures (Figure 2). For patients older than 2.5 months at surgery, the ventilator days and ICU and total hospital stay were independent of the number of concurrent surgeries.

\section{DISCUSSION}

The present multicenter study was uniquely suited to explore the effects of differences in surgical technique and
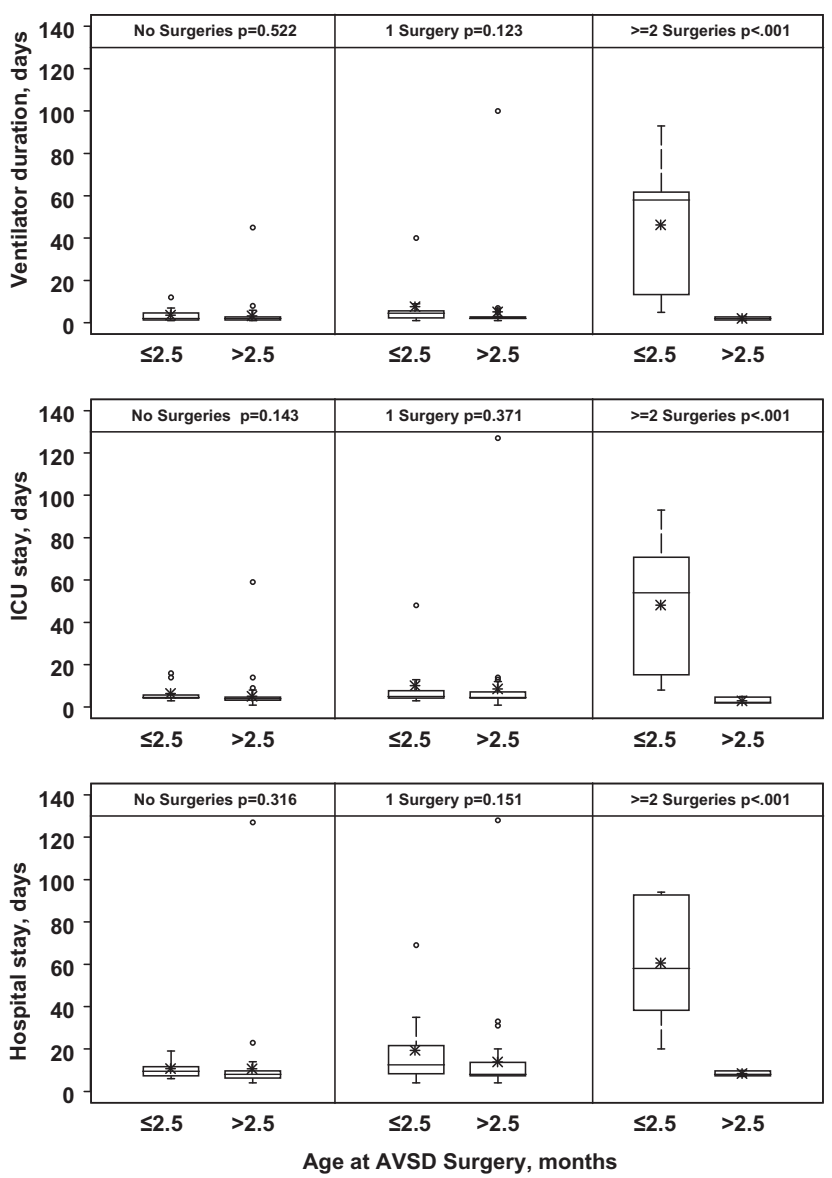

FIGURE 2. Box plots of ventilator duration, intensive care unit (ICU) stay, and hospital stay by age group and number of concurrent surgeries. $P$ values from linear regression modeling of log-transformed outcome. Asterisk denotes group mean. Lower, middle, and upper edges of boxes represent 25th, 50th, and 75th percentiles, respectively.

the factors related to specified controversial demographic variables such as age and the presence of trisomy 21 on outcome measures. The surgical repair of complete AVSD is routinely performed during infancy, although no consensus has been reached regarding the ideal timing to balance the risk of congestive heart failure symptoms against the greater technical operative risks. Single-center reports encompassing more than 1 decade have demonstrated that earlier repair at $<3$ or 4 months of age can be associated with lower hospital mortality ${ }^{14,15}$ and a lower risk of later reoperation compared with those undergoing repair at an older age. ${ }^{15}$ In our series, the median age at repair was 3.7 months, and the outcomes were generally good. The in-hospital mortality rate was low $(2.5 \%)$, and reoperation within 6 months for severe LAVVR occurred in $4 \%$, commensurate with the data from recent single-center reports. ${ }^{16}$ Significant residual atrial or ventricular shunts were uncommon and tended to be small, with resolution within 6 months of repair. Similar to other reports, moderate or greater LAVVR, as assessed by 
echocardiography, remained the most common sequelae and was present in $22 \%$ at 6 months. ${ }^{17}$

Classic repairs for complete AVSD have used either a single patch to close both atrial and ventricular defects, necessitating division and resuspension of the common atrioventricular valve, ${ }^{4}$ or a double patch technique in which the valve is not divided and individual patches are used to close each defect. ${ }^{5}$ More recently, a modified single patch technique has been described that avoids the use of a patch to close the VSD (Australian technique). ${ }^{6,7}$ Although reports comparing the various techniques have been limited by era, surgeon, and institutional experience, general equivalence with respect to efficacy has been suggested for the short- to medium-term outcomes. ${ }^{16,18}$ Overall, the double patch technique was performed more often $(72 \%)$ in our series; however, we found considerable variation in the repair type across the participating centers. Previous studies comparing the outcomes of different surgical techniques for the repair of complete AVSD have been limited to single-center reports using historical controls. Our multicenter, contemporary findings have generally supported the findings from these previous retrospective reports and showed no differences in residual septal defects, degree of LAVVR, need for reoperation by 6 months, or postoperative ICU and hospital stay by repair type. In our cohort, the children who underwent the Australian technique were younger and less likely to have trisomy 21 . Although we did not have the data to confirm this, one might speculate that the subgroup of patients without trisomy 21 might be more likely to have a comparatively smaller VSD, making the Australian type repair more appealing. We corroborated previously noted differences in surgical management with the Australian technique requiring shorter bypass and crossclamp times. ${ }^{16,18}$ Although speculative, it is plausible that a surgeon might have selected the Australian technique as the preferred repair in the youngest and most symptomatic patients to allow the surgery to be completed faster and with less manipulation of the common valve.

We found important differences that were previously unreported. First, a lower frequency of additional annuloplasty modifications of the LAVV was found among those repaired with the Australian technique ( $0 \%$ Australian, $14 \%$ single patch, $30 \%$ double patch). Second, the need to return to bypass for surgical revision of the initial operation occurred more frequently with the Australian technique than with the other techniques. This might have reflected the younger ages at repair or the surgeon and institutional learning curve with this newer type of repair. Our analysis failed to identify a superior method for complete AVSD repair. We surmised that it is surgeon preference, institutional experience, and familiarity with a specific technique, rather than the technique itself, that provides the best outcomes.

Historically, patients with AVSD and trisomy 21 compared with those without trisomy 21 have been reported to have better outcomes with fewer reoperations. ${ }^{19,20}$ More recent reports have suggested that the presence of trisomy 21 has no effect on postoperative survival. ${ }^{21}$ In our series, some preoperative and intraoperative differences were present between the 2 groups, but the outcomes were similar. Fewer patients with trisomy 21 had moderate or severe atrioventricular valve regurgitation on the preoperative echocardiogram. Significantly fewer patients with trisomy 21 underwent repair using the Australian technique (5\% vs $29 \%$ ). We also found a trend toward decreased early reoperation by 6 months in those with trisomy $21(2 \%$ vs $13 \%)$. Although others have suggested the "protective" influence of trisomy 21 for infants undergoing surgery for AVSD might in part be because they are more likely to have the balanced form of AVSD and less likely to have heterotaxy syndrome, we did not collect the data required to test those features. ${ }^{22}$ The most striking difference concerned the comparative growth issues. Although it is well known that subjects with trisomy 21 will be smaller than those without trisomy 21 , and, among those with trisomy 21 , those with congenital heart disease will be smaller than those without heart defects, ${ }^{23}$ growth comparisons between the children with and without trisomy 21 and the same heart defect have not been previously reported. We found those without trisomy 21 were much more likely to have growth failure at surgery $(71 \%$ vs $21 \%)$. At 6 months after repair, the patients without trisomy 21 exhibited considerable "catch up" growth but were still more likely to have growth failure ( $27 \%$ vs $7 \%$ ). Patients with unrepaired AVSD and trisomy 21 have greater pulmonary vascular resistance than children with normal chromosomes. ${ }^{24}$ Therefore, subjects without trisomy 21 might be expected preoperatively to have a greater net left to right shunt and more growth failure compared with those with trisomy 21 .

An ongoing trend is present toward earlier repair of AVSD; thus, we attempted to find a lower bound for patient referral in this group. Considering the age at repair as a continuous variable, we found that adverse outcomes were negatively correlated with repair at age younger than 2.5 months but did not vary by age beyond 2.5 months. When comparing these 2 groups (using 2.5 months as the cutoff), we found some important differences. The repair type differed by age at surgery, with fewer repairs using the single patch technique and more using the Australian technique in the younger group. The younger group was more likely to undergo circulatory arrest that appeared directly related to the need to perform concurrent additional surgeries such as aortic arch augmentation. The resource use was also strikingly different. Subjects undergoing repair at younger than 2.5 months old required a longer duration of mechanical ventilation and longer ICU and total hospital stays.

The present study was sponsored by the Pediatric Heart Network, an entity devoted to creating evidence-based medical practice in pediatric cardiology and cardiac 
surgery. The 7 participating surgical centers involved in the present study appreciated the importance of sharing the outcome data and anticipated that the current data might be used as a comparative benchmark for efforts at additional improvements in the treatment of patients with complete AVSD.

\section{Study Limitations}

The multicenter and observational nature of the present study precluded standardization and central interpretation of all measurements. Reliable and validated echocardiographic methods for the quantification of LAVVR in pediatric patients were not available; thus, we chose to use a qualitative assessment according to the color Doppler evaluation by a single core laboratory echocardiographer. The follow-up of the present cohort was limited to 6 months, precluding assessment of longer term complications or the need for reoperation. The nonrandom distribution of repair type limited the ability to distinguish between age effect and surgical technique. Similarly, the age at surgery was not randomly distributed but was skewed toward an older age; therefore, the smaller number of subjects with repairs undertaken before 2.5 months of age might have limited the power to detect associations between age at repair and certain outcomes.

\section{CONCLUSIONS}

We evaluated the outcomes after repair of complete AVSD, with particular attention to surgical repair type, age at surgery, and the presence of trisomy 21 . We found marked institutional variability in repair type in the current era. Mortality and morbidity, despite the repair type or presence of trisomy 21, were low. Age at repair of 2.5 months or younger and the need for concurrent surgical procedures were not associated with residual defects or the degree of LAVVR but were associated with longer postoperative ventilator, ICU, and total hospital duration.

\section{References}

1. Crawford FA Jr, Stroud MR. Surgical repair of complete atrioventricular septal defect. Ann Thorac Surg. 2001;72:1621-8.

2. Larrazabal LA, del Nido PJ, Jenkins KJ, Gauvreau K, Lacro R, Colan SD, et al. Measurement of technical performance in congenital heart surgery: a pilot study. Ann Thorac Surg. 2007;83:179-84.

3. Jacobs JP, Burke RP, Quintessenza JA, Mavroudis C. Congenital Heart Surgery Nomenclature and Database Project: atrioventricular canal defect. Ann Thorac Surg. 2000;69:S36-43.
4. McGoon DC, DuShane JW, Kirklin JW. The surgical treatment of endocardial cushion defects. Surgery. 1959;46:185-96.

5. Maloney JV Jr, Marable SA, Mulder DG. The surgical treatment of common atrioventricular canal. J Thorac Cardiovasc Surg. 1962;43:84-96.

6. Wilcox BR, Jones DR, Frantz EG, Brink LW, Henry GW, Mill MR, et al. Anatomically sound, simplified approach to repair of "complete" atrioventricular septal defect. Ann Thorac Surg. 1997;64:487-93.

7. Nicholson IA, Nunn GR, Sholler GF, Hawker RE, Cooper SG, Lau KC, et al. Simplified single patch technique for the repair of atrioventricular septal defect. J Thorac Cardiovasc Surg. 1999;118:642-6.

8. Padala M, Vasilyev NV, Owen JW Jr, Jimenez JH, Dasi LP, del Nido PJ, et al. Cleft closure and undersizing annuloplasty improve mitral repair in atrioventricular canal defects. J Thorac Cardiovasc Surg. 2008;136:1243-9.

9. Styles ME, Cole TJ, Dennis J, Preece MA. New cross sectional stature, weight, and head circumference references for Down's syndrome in the UK and Republic of Ireland. Arch Dis Child. 2002;87:104-8.

10. Kuczmarski RJ, Odgen CL, Grummer-Strawn LM. CDC growth charts: United States. Advance data from vital and health statistics; no 314. Hyattsville, Maryland: National Center for Health Statistics; 2000.

11. Ross RD, Bollinger RO, Pinsky WW. Grading the severity of congestive heart failure in infants. Pediatr Cardiol. 1992;13:72-5.

12. Sluysmans T, Colan SD. Theoretical and empirical derivation of cardiovascular allometric relationships in children. J Appl Physiol. 2005;99:445-57.

13. Tlaskal T, Hucin B, Marek J, Chaloupecky V, Kostelka M, Janousek J, et al. Individualized repair of the left atrioventricular valve in spectrum of atrioventricular septal defect. J Cardiovasc Surg (Torino). 1997;38:233-9.

14. Michielon G, Stellin G, Rizzoli G, Casarotto DC. Repair of complete common atrioventricular canal defects in patients younger than four months of age. Circulation. 1997;96(9 Suppl):II-22.

15. Stellin G, Vida VL, Milanesi O, Rizzoli G, Rubino M, Padalino MA, et al. Surgical treatment of complete A-V canal defects in children before 3 months of age. Eur J Cardiothorac Surg. 2003;23:187-93.

16. Backer CL, Stewart RD, Bailliard F, Kelle AM, Webb CL, Mavroudis C. Complete atrioventricular canal: comparison of modified single-patch technique with two-patch technique. Ann Thorac Surg. 2007;84:2038-46.

17. Singh RR, Warren PS, Reece TB, Ellman P, Peeler BB, Kron IL. Early repair of complete atrioventricular septal defect is safe and effective. Ann Thorac Surg. 2006;82:1598-601.

18. Halit V, Oktar GL, Imren VY, Iriz E, Erer D, Kula S, et al. Traditional single patch versus the "Australian" technique for repair of complete atrioventricular canal defects. Surg Today. 2008;38:999-1003.

19. Weintraub RG, Brawn WJ, Venables AW, Mee RB. Two-patch repair of complete atrioventricular septal defect in the first year of life: results and sequential assessment of atrioventricular valve function. J Thorac Cardiovasc Surg. 1990;99: 320-6.

20. Najm HK, Coles JG, Endo M, Stephens D, Rebeyka IM, Williams WG, et al. Complete atrioventricular septal defects: results of repair, risk factors, and freedom from reoperation. Circulation. 1997;96(9 Suppl):II-5.

21. Miller A, Siffel C, Lu C, Riehle-Colarusso T, Frias JL, Correa A. Long-term survival of infants with atrioventricular septal defects. J Pediatr. Epub 2010 Mar 12.

22. Formigari R, Di Donato RM, Gargiulo G, Di Carlo D, Feltri C, Picchio FM, et al. Better surgical prognosis for patients with complete atrioventricular septal defect and Down's syndrome. Ann Thorac Surg. 2004;78:666-72.

23. Cronk C, Crocker AC, Pueschel SM, Shea AM, Zackai E, Pickens G, et al. Growth charts for children with Down syndrome: 1 month to 18 years of age. Pediatrics. 1988;81:102-10.

24. Clapp S, Perry BL, Farooki ZQ, Jackson WL, Karpawich PP, Hakimi M, et al. Down's syndrome, complete atrioventricular canal, and pulmonary vascular obstructive disease. J Thorac Cardiovasc Surg. 1990;100:115-21. 


\section{APPENDIX}

National Heart, Lung, and Blood Institute: Gail Pearson, Victoria Pemberton, Mario Stylianou, Marsha Mathis.

Network Chair: University of Texas Southwestern Medical Center, Lynn Mahony.

Data Coordinating Center: New England Research Institutes, Lynn Sleeper (Primary Investigator), Steven Colan, Gloria Klein, Dianne Gallagher, Minmin Lu, Paul Mitchell.*

Clinical Site Investigators: Children's Hospital Boston, Jane W. Newburger (Primary Investigator), Ashwin Prakash, Renee Margossian, Jami Levine, Ellen McGrath, Carolyn Dunbar-Masterson; Children's Hospital of New York, Wyman Lai (Primary Investigator), William Hellenbrand, Marc Richmond, Beth Printz*, Darlene Servedio*, Rosalind Korsin; Children's Hospital of Philadelphia, Victoria L. Vetter (Primary Investigator), Meryl Cohen, Sandra DiLullo, Marisa Nolan; North Carolina Consortium: Duke University, East Carolina University, Wake Forest Univer- sity, Page A. W. Anderson (Primary Investigator; deceased), Jennifer Li (Primary Investigator), Wesley Covitz, Kari Crawford, Michael Hines, James Jaggers, Charlie Sang, Jr., Lori Jo Sutton, Mingfen Xu; Medical University of South Carolina, J. Philip Saul (Primary Investigator), Andrew Atz, Girish Shirali, Jennifer Young*; Primary Children's Medical Center and the University of Utah, L. LuAnn Minich (Primary Investigator), John A. Hawkins, Linda M. Lambert, Richard V. Williams; Hospital for Sick Children, Toronto, Brian McCrindle (Primary Investigator), Fraser Golding, Nancy Slater, Elizabeth Radojewski.

Echocardiography Core Laboratory: Children's Hospital of Boston, Steven Colan, Ron Lacro.

Protocol Review Committee: Michael Artman (Chair), Daniel Bernstein, Christopher A. Caldarone, Timothy Feltes, Julie Johnson, Jeffrey Krischer, G. Paul Matherne.

Data and Safety Monitoring Board: John Kugler (Chair), David J. Driscoll, Kathryn Davis, Sally A. Hunsberger, Mark Galantowicz, Thomas J. Knight, James Tweddell, Catherine L. Webb, Lawrence Wissow. 